\title{
A complete parameterisation of the relative humidity and wavelength dependence of the refractive index of hygroscopic inorganic aerosol particles
}

\author{
Michael I. Cotterell ${ }^{1,2,3}$, Rose E. Willoughby ${ }^{1}$, Bryan R. Bzdek ${ }^{1}$, Andrew J. Orr-Ewing ${ }^{1}$, and Jonathan P. Reid ${ }^{1}$ \\ ${ }^{1}$ School of Chemistry, University of Bristol, Bristol, BS8 1TS, UK \\ ${ }^{2}$ College for Engineering, Mathematics and Physical Sciences, University of Exeter, EX4 4QF, UK \\ ${ }^{3}$ Aerosol Observation Based Research, Met Office, EX1 3PB, UK
}

Correspondence to: Jonathan P. Reid (j.p.reid@bristol.ac.uk)

Received: 23 March 2017 - Discussion started: 3 April 2017

Revised: 4 July 2017 - Accepted: 11 July 2017 - Published: 22 August 2017

\begin{abstract}
Calculations of aerosol radiative forcing require knowledge of wavelength-dependent aerosol optical properties, such as single-scattering albedo. These aerosol optical properties can be calculated using Mie theory from knowledge of the key microphysical properties of particle size and refractive index, assuming that atmospheric particles are well-approximated to be spherical and homogeneous. We provide refractive index determinations for aqueous aerosol particles containing the key atmospherically relevant inorganic solutes of $\mathrm{NaCl}, \mathrm{NaNO}_{3},\left(\mathrm{NH}_{4}\right)_{2} \mathrm{SO}_{4}, \mathrm{NH}_{4} \mathrm{HSO}_{4}$ and $\mathrm{Na}_{2} \mathrm{SO}_{4}$, reporting the refractive index variation with both wavelength (400-650 nm) and relative humidity (from $100 \%$ to the efflorescence value of the salt). The accurate and precise retrieval of refractive index is performed using singleparticle cavity ring-down spectroscopy. This approach involves probing a single aerosol particle confined in a Bessel laser beam optical trap through a combination of extinction measurements using cavity ring-down spectroscopy and elastic light-scattering measurements. Further, we assess the accuracy of these refractive index measurements, comparing our data with previously reported data sets from different measurement techniques but at a single wavelength. Finally, we provide a Cauchy dispersion model that parameterises refractive index measurements in terms of both wavelength and relative humidity. Our parameterisations should provide useful information to researchers requiring an accurate and comprehensive treatment of the wavelength and relative humidity dependence of refractive index for the inorganic component of atmospheric aerosol.
\end{abstract}

\section{Introduction}

The current best estimate of aerosol effective radiative forcing (relative to the year 1750) is $-0.9\left({ }_{-1.0}^{+0.8}\right) \mathrm{W} \mathrm{m}^{-2}$, in which the uncertainty range represents the $5-95 \%$ confidence limits (Alexander et al., 2013). Reducing the large uncertainty associated with aerosol radiative forcing (RF) is crucial to improving the representation of aerosol in climate models. Top-of-the-atmosphere radiative forcing $\left(\mathrm{RF}_{\mathrm{TOA}}\right)$ is a common metric for assessing the contribution of different aerosol particles to the warming or cooling of Earth's atmosphere (Alexander et al., 2013; Erlick et al., 2011; Haywood and Boucher, 2000; Ravishankara et al., 2015). $\mathrm{RF}_{\mathrm{TOA}}$ can be estimated for a uniform, optically thin layer of aerosol in the lower troposphere using (Dinar et al., 2008)

$$
\mathrm{RF}_{\mathrm{TOA}}=S_{0} D T_{\mathrm{at}}^{2}\left(1-A_{\mathrm{c}}\right)\left[2 R_{\mathrm{S}}(1-\bar{\omega})-\bar{\beta} \bar{\omega}\left(1-R_{\mathrm{S}}\right)^{2}\right]
$$

in which $S_{0}$ is the solar constant $\left(1370 \mathrm{~W} \mathrm{~m}^{-2}\right), D$ is the fractional day length, $T_{\text {at }}$ is the solar atmospheric transmittance, $A_{\mathrm{c}}$ is the fractional cloud cover and $R_{\mathrm{S}}$ is the surface reflectance. The use of satellite, aeroplane and ground-based observations allows quantification of the geographical variation in $D, T_{\mathrm{at}}, A_{\mathrm{c}}$ and $R_{\mathrm{s}}$. Importantly, Eq. (1) indicates the dependence of $\mathrm{RF}_{\mathrm{TOA}}$ on the spectrally weighted singlescattering albedo, $\bar{\omega}$, and the spectrally weighted backscattered fraction, $\bar{\beta}$. Under the assumptions that a particle is both spherical and homogeneous, $\bar{\omega}$ and $\bar{\beta}$ (in addition to other aerosol optical properties) can be calculated using Mie theory with input values of the aerosol particle size $(a)$ and 
the complex refractive index (RI, $m=n+k i$ ) dependent on wavelength $(\lambda)$ (Bohren and Huffman, 1998; Hess et al., 1998; Levoni et al., 1997). Although measurements of particle size and size distribution are relatively straightforward using techniques such as aerodynamic particle sizing and differential mobility analysis (DMA), the measurement of $m$ is more challenging, particularly as aqueous aerosol droplets commonly exist at supersaturated solute concentrations that are not accessible in bulk measurements. Zarzana et al. estimated that an uncertainty in the real component of the RI, $n$, of $0.003(0.2 \%)$ leads to an uncertainty in RF of $1 \%$, for non-absorbing $\left(\mathrm{NH}_{4}\right)_{2} \mathrm{SO}_{4}$ particles with a 75 or $100 \mathrm{~nm}$ radius (Zarzana et al., 2014). Meanwhile, Moise et al. reported that variation in $n$ from 1.4 to 1.5 resulted in an increase in the radiative forcing by $12 \%$ (Moise et al., 2015). Therefore, any strategy to reduce the uncertainty in $\mathrm{RF}_{\mathrm{TOA}}$ that starts from characterisations of aerosol microphysical properties (a bottom-up approach) requires the development of new in situ techniques for the accurate characterisation of refractive indices dependent on wavelength and relative humidity ( $\mathrm{RH})$.

Tang et al. levitated single, laboratory-generated aerosol particles in an electrodynamic balance (EDB), measuring relative changes in the droplet mass and recording the elastic light scattered at a fixed angle relative to the propagation direction of a $633 \mathrm{~nm}$ laser beam. By comparing the measured light scattering traces to calculations from Mie theory, $n$ was parameterised as a function of RH for a range of inorganic aqueous solution droplets, key components of nonabsorbing atmospheric aerosol. Tang's parameterisations of $n_{633}$ for aqueous inorganic solutes have become a benchmarking standard for new techniques measuring refractive index (Cotterell et al., 2015b; Hand and Kreidenweis, 2002; Mason et al., 2012, 2015) and are used as reference RI data for RF calculations of aqueous inorganic aerosol (Erlick et al., 2011). However, Tang's measurements were limited to $\lambda=633 \mathrm{~nm}$ and knowledge of the optical dispersion is required to calculate spectrally weighted values of the singlescattering albedo and backscatter function.

Another method for determining the RI of a particle is to fit the measured size dependence of optical cross sections to Mie theory (Moise et al., 2015). In particular, the interaction of light with an aerosol particle is governed by the particle extinction cross section, $\sigma_{\text {ext }}$, (Bohren and Huffman, 1998; Miles et al., 2011a) and measurements of $\sigma_{\text {ext }}$ using cavityenhanced methods are, in principle, highly precise. Ensemble broadband cavity-enhanced spectroscopy involves $\sigma_{\text {ext }}$ measurements on a cloud of aerosol particles over a broad range of wavelengths. Zhao et al. (2013) have developed an ensemble broadband cavity-enhanced spectrometer for measurements of $\sigma_{\text {ext }}$ over the wavelength range $445-480 \mathrm{~nm}$ and reported measurements of $\left(\mathrm{NH}_{4}\right)_{2} \mathrm{SO}_{4}$ aerosol (Zhao et al., 2013). Rudich and co-workers developed an ensemble broadband cavity-enhanced spectrometer for the wavelength range 360-420 nm (Flores et al., 2014a, b; Washenfelder et al., 2013). From measurements of Suwannee River ful- vic acid aerosol (a weakly absorbing species), $m$ was measured to be $1.71( \pm 0.02)+0.07( \pm 0.06) i$ at $360 \mathrm{~nm}$ and $1.66( \pm 0.02)+0.06( \pm 0.04) i$ at $420 \mathrm{~nm}$ (Washenfelder et al., 2013). These uncertainties in the retrieved $m$ limit the accuracy of RF calculations.

Ensemble cavity ring-down spectroscopy (E-CRDS) is a related cavity-enhanced spectroscopy technique used for $\sigma_{\text {ext }}$ measurements for aerosol particles in both the laboratory (Dinar et al., 2008; Lang-Yona et al., 2009; Mason et al., 2012) and in the field (Baynard et al., 2007; Langridge et al., 2011). In E-CRDS, a flow of aerosol is introduced into an optical cavity consisting of two highly reflective mirrors in which the aerosol ensemble is probed using CRDS and an extinction coefficient, $\alpha_{\text {ext }}$, is measured. In combination with measurements of particle number concentration, $N$, using a condensation particle counter, $\sigma_{\text {ext }}$ is calculated using $\sigma_{\text {ext }}=\alpha_{\text {ext }} / N$. However, uncertainty in the population distribution of aerosol within the cavity ring-down beam and errors in the measured $N$ can lead to imprecise measurements of $\sigma_{\text {ext }}$ (Miles et al., 2011b). By size selecting aerosol using DMA prior to admitting an ensemble into the optical cavity, the variation in $\sigma_{\text {ext }}$ with particle size is measured and the particle RI can be retrieved. However, the accuracy and precision in the retrieved RIs are often too poor for reliable RF calculations owing to the combination of imprecise $\sigma_{\text {ext }}$ measurement and the significant systematic errors that can derive from the DMA size selection process. Mason et al. reported a precision of $\pm 0.02(\sim 1.4 \%)$ in the retrieved $n$ from E-CRDS measurements of $\mathrm{NaNO}_{3}$ particles at a range of RH values (Mason et al., 2012), while Miles et al. 2011b found that errors in the measured $N$ can alone introduce a $\sim 2.5 \%$ uncertainty in the retrieved $n$, therefore limiting the precision of this technique. Under a scenario incorporating best-case errors in variables governing E-CRDS $\sigma_{\text {ext }}$ measurements, a theoretical study by Zarzana and co-workers estimated the accuracy in the $n$ retrieved from E-CRDS to be $0.6 \%$ at best from simulations of $\sigma_{\text {ext }}$ measurements for nonabsorbing $\left(\mathrm{NH}_{4}\right)_{2} \mathrm{SO}_{4}$ particles at 12 discrete particle sizes (Zarzana et al., 2014).

Probing a single particle, instead of an aerosol ensemble, resolves many of the problems inherent in E-CRDS that degrade the RI retrieval precision. We have previously reported the application of two single-particle cavity ring-down spectroscopy (SP-CRDS) instruments to measure $\sigma_{\text {ext }}$ at wavelengths of $\lambda=405$ and $532 \mathrm{~nm}$ for single particles confined within a Bessel laser beam (BB) optical trap (Cotterell et al., 2015a, b; Mason et al., 2015; Walker et al., 2013). No measurement of particle number density is required and measurements of $\sigma_{\text {ext }}$ are made with continuous variation in the particle size as the particle evolves with time, either through an RH change or through particle-gas partitioning of semivolatile components. In our measurements, the particle size is precisely determined from fitting the angularly resolved elastic light-scattering distributions to Mie theory. For singlecomponent evaporation measurements, we measured the pre- 
cision in retrievals of $n$ to be \pm 0.0007 for the $532 \mathrm{~nm} \mathrm{SP}$ CRDS instrument (Mason et al., 2015) and \pm 0.0012 using the $405 \mathrm{~nm}$ SP-CRDS instrument (Cotterell et al., 2015b). Also, we demonstrated the retrieval of RI from hygroscopic response measurements for aqueous droplets containing inorganic solutes (Cotterell et al., 2015a, b). By simulating $\sigma_{\mathrm{ext}}$ data using the parameters of the $532 \mathrm{~nm}$ SP-CRDS instrument, we demonstrated the expected retrieval accuracy in $n$ to be $0.0002(0.014 \%)$ for single-component particles evaporating over the radius range $1-2 \mu \mathrm{m}$. Meanwhile, we showed that the retrieval accuracy is $<0.001$ for coarse-mode particles when $n$ varies with particle size, such as in a hygroscopic response measurement (Cotterell et al., 2016).

In this paper, we report the application of the 405 and $532 \mathrm{~nm}$ SP-CRDS instruments for the measurement of $n$ at the four wavelengths of $405,473,532$ and $633 \mathrm{~nm}\left(n_{405}\right.$, $n_{473}, n_{532}$ and $n_{633}$, respectively). In particular, we report comprehensive RI measurements for the hygroscopic response of aqueous droplets containing atmospherically relevant inorganic solutes and quantify the RI retrieval precision. We compare the differences in the RI retrieval precision and accuracy when sizing particles using either (i) light elastically scattered from the BB optical trap or (ii) light elastically scattered from a Gaussian probe beam. Measurements of $n_{633}$ as a function of RH from phase functions, Raman spectroscopy (from aerosol optical tweezer (AOT) measurements) and from the Tang et al. (Tang et al., 1997; Tang and Munkelwitz, 1994) parameterisation are compared. Finally, our multi-wavelength RI retrievals, combined with $n_{650}$ measurements from aerosol optical tweezers, $n_{589}$ measurements of bulk solutions and the $n_{633}$ descriptions provided by Tang et al. (Tang et al., 1997; Tang and Munkelwitz, 1994), are parameterised using an optical dispersion model. The following section describes the 405 and $532 \mathrm{~nm}$ SP-CRDS instruments and the aerosol optical tweezer instrument, while Sect. 3 reports the retrieved RI variation with RH for aqueous aerosol particles containing the inorganic solutes $\mathrm{NaCl}$, $\mathrm{NaNO}_{3},\left(\mathrm{NH}_{4}\right)_{2} \mathrm{SO}_{4}, \mathrm{NH}_{4} \mathrm{HSO}_{4}$, or $\mathrm{Na}_{2} \mathrm{SO}_{4}$ and compares different methods of retrieving $n_{\lambda}$. Indeed, these solutes represent the most abundant species found in inorganic atmospheric aerosol. Finally, Sect. 4 presents a Cauchy dispersion model for parameterising the variation in the RI with both wavelength and $\mathrm{RH}$.

\section{Experimental and numerical methods}

\section{Aerosol optical tweezers}

Measurements of RI at $650 \mathrm{~nm}$ were accomplished using commercial AOTs (AOT-100, Biral). The experimental setup has been described in detail previously (Davies and Wilson, 2016; Haddrell et al., 2017). Briefly, a single aqueous droplet from a plume produced by a medical nebuliser (NE-U22, Omron) is captured by a gradient force optical trap formed from focussing a $532 \mathrm{~nm}$ laser (Opus 2W, Laser Quantum) through a high numerical aperture microscope objective (Olympus PLFLN 100×). Inelastically backscattered (Raman) light is imaged onto the entrance slit of a $0.5 \mathrm{~m}$ focal length spectrograph (Princeton Instruments, Action Spectra SP-2500i), dispersed by a 1200 line pairs per millimetre grating onto a cooled charge-coupled device (CCD) camera. The Raman spectrum of a spherical droplet consists of a broad underlying Stokes band with superimposed resonant structure at wavelengths commensurate with whispering gallery modes (WGMs), from which the radius, RI, and dispersion can be determined with accuracies better than $2 \mathrm{~nm}, 0.0005$ and $3 \times 10^{-8} \mathrm{~cm}$ respectively (Preston and Reid, 2013). RH in the trapping chamber is controlled by adjusting the relative flows of dry and humidified nitrogen and is measured to $\pm 2 \%$ using a capacitance probe (Honeywell HIH-4602C). A typical experiment involves trapping an aqueous droplet containing one of the studied solutes, decreasing the $\mathrm{RH}$ in discrete steps over several hours, and monitoring the RHdependent changes to droplet radius, refractive index and dispersion. Note that because dispersion is also determined, it is possible to compare refractive indices measured using the optical tweezers with other approaches at different wavelengths (e.g. $633 \mathrm{~nm}$ by Tang et al.).

\section{Single-particle cavity ring-down spectroscopy instrument}

Figure 1 summarises the experimental arrangement of the 405 and $532 \mathrm{~nm} \mathrm{SP-CRDS} \mathrm{instruments.} \mathrm{The} 532 \mathrm{~nm} \mathrm{SP-}$ CRDS instrument has been described previously (Mason et al., 2015), while Cotterell et al. (2015a) describes modifications to the instrument to improve particle size retrieval. The $405 \mathrm{~nm}$ SP-CRDS instrument is described elsewhere (Cotterell et al., 2015b), and recent modifications to this instrument to improve size determination are described below. The following section provides a general description of $\sigma_{\mathrm{ext}}$ and elastic light-scattering measurements using SP-CRDS.

\subsection{Overview of single-particle cavity ring-down spectroscopy}

\section{The continuous-wave cavity ring-down spectrometer}

The single-particle CRDS measurements were performed on two separate instruments summarised in Fig. 1, with each instrument performing CRDS at either 405 or $532 \mathrm{~nm}$. The beam from a continuous-wave single-mode laser (with a spectral bandwidth $<5 \mathrm{MHz}$ ) passes through an acoustooptic modulator (AOM). The first-order diffraction spot is injected into an optical cavity, while the zero and higher-order spots are attenuated with beam blocks. The optical cavity consists of two highly reflective mirrors with radii of curvature of $1 \mathrm{~m}$ and reflectivities $>99.98 \%$ at the CRDS wavelength and has a free spectral range of $\sim 300 \mathrm{MHz}$. The cav- 
(a) $532 \mathrm{~nm}$ SP-CRDS

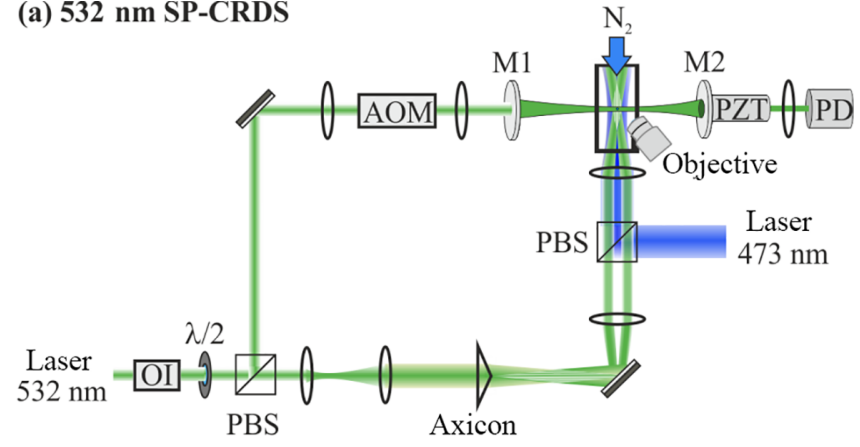

(b) $405 \mathrm{~nm}$ SP-CRDS

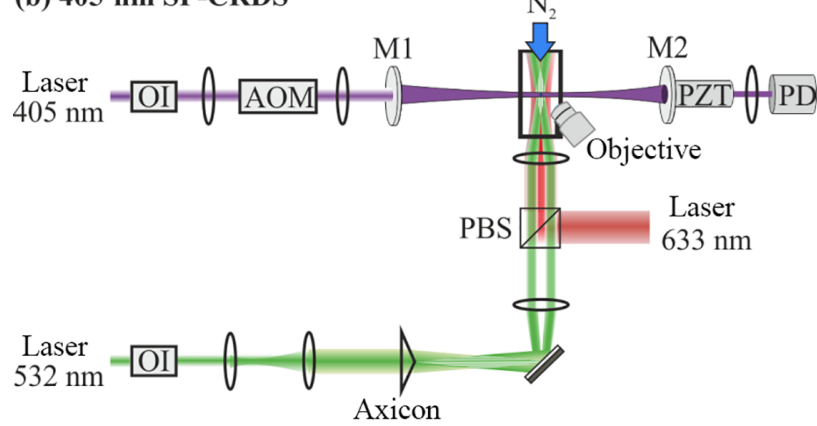

Figure 1. Schematic diagrams of the two SP-CRDS instruments used in this work. OI is an optical isolator, $\lambda / 2$ is a half-wave plate, PBS is a polarising beam splitter cube, AOM is an acousto-optic modulator, PZT represents a piezo ring actuator, PD is a photodiode, and M1 and M2 are highly reflective mirrors of the optical cavity. The $633 \mathrm{~nm}$ laser in (b) is used in selected measurements indicated in the text.

ity is aligned such that the $\mathrm{TEM}_{00}$ mode is preferentially excited. A piezo ring actuator, affixed to the rear cavity mirror, continuously varies the cavity length across several free spectral ranges. When the cavity length is such that a longitudinal cavity mode is excited, a photodiode monitors the build-up of light inside the cavity and measures the intensity escaping from the rear mirror as an output voltage, $\mathrm{V}$, which is sent to both a Compuscope digitizer and a digital delay generator. The digital delay generator outputs a $5 \mathrm{~V}$ transistortransistor logic (TTL) pulse to the AOM when the leading edge of the photodiode signal reaches a $1 \mathrm{~V}$ threshold value, rapidly switching off the first-order AOM diffraction beam and initiating a ring-down decay. The subsequent time variation in $\mathrm{V}$ obeys a single exponential decay and is fitted to $\mathrm{V}=\mathrm{V}_{0} \exp (-t / \tau)+b$, with $\tau$ the characteristic ring-down time (RDT) and $b$ a baseline offset. RDTs are measured at a rate of 5-10 Hz. To reduce the contributions of airborne dust particles to light extinction and to prevent the mirrors getting dirty, nitrogen gas flows are directed across the faces of the cavity mirrors and through flow tubes that extend to a trapping cell at the centre of the cavity.

\section{The Bessel beam optical trap}

Both the 405 and $532 \mathrm{~nm}$ SP-CRDS instruments use a $532 \mathrm{~nm}$ laser beam to generate a BB optical trap. A Gaussian $532 \mathrm{~nm}$ laser beam is passed through a $2^{\circ}$ axicon to produce a $\mathrm{BB}$, which has a circularly symmetric intensity profile consisting of a central core and multiple rings. A pair of lenses reduces the $\mathrm{BB}$ core diameter to $3-5 \mu \mathrm{m}$. A $45^{\circ}$ mirror propagates this beam vertically into the trapping cell. This mirror and the trapping cell are mounted on the same translation stage, allowing the position of the BB optical trap to be translated in the horizontal transverse direction to the CRDS optical axis. In the trapping cell, the radiation pressure exerted by the $\mathrm{BB}$ on a trapped particle is balanced by a humidified nitrogen gas flow of 100-200 sccm, allowing control over RH. This gas flow is also used to purge the cell of excess aerosol. The RH inside the trapping cell is monitored using a capacitance probe. A plume of aerosol particles is introduced into the cell using a medical nebuliser. Typically, a single aerosol particle is isolated from this plume by the BB optical trap. Occasionally multiple particles are trapped, in which case the trapping cell is evacuated and aerosol particles are again nebulised into the cell. This process is repeated until only a single particle is trapped.

\section{Size and RI retrieval using phase function images}

A camera coupled to a high numerical aperture objective, positioned at $90^{\circ}$ with respect to the $\mathrm{BB}$ propagation direction, records images (referred to as phase function, PF, images) that describe the angular variation in elastically scattered light at a selected polarisation. For $532 \mathrm{~nm}$ SP-CRDS measurements, we record PFs of the light elastically scattered from a $473 \mathrm{~nm}$ probe laser beam. The probe beam is aligned collinearly to the BB propagation direction using a polarisation beam splitter (PBS) cube, the alignment of which is shown in Fig. 1a. The PBS merges the two beams prior to the final lens $(f=50 \mathrm{~mm})$ and, therefore, the probe beam is weakly focussed into the trapping cell. In the trapping cell, the probe beam has a Gaussian transverse intensity profile and a beam diameter $\sim 8$ times larger than the BB core diameter. A $532 \mathrm{~nm}$ laser line filter ensures that the camera does not collect elastically scattered light from the BB. For $405 \mathrm{~nm}$ SP-CRDS measurements, we predominantly collect PFs of light elastically scattered from the beam forming the BB optical trap or occasionally from a $633 \mathrm{~nm}$ probe laser beam (LHP073, Melles Griot). The $633 \mathrm{~nm}$ probe beam is aligned collinearly to the $\mathrm{BB}$ propagation direction and is merged with the BB using a PBS cube as shown in Fig. 1b. In the trapping cell, the probe beam has a Gaussian transverse intensity profile and a beam diameter that is $\sim 3$ times larger than the BB core diameter. When recording $633 \mathrm{~nm}$ PFs, a $532 \mathrm{~nm}$ laser line filter ensures that the imaging camera does not collect elastically scattered light from the BB, while this 
filter is removed when collecting $532 \mathrm{~nm}$ PFs corresponding to BB illumination.

The variation in particle radius and $n_{\lambda}$ is determined by fitting the complete measured PF data set to Mie theory in a self-consistent step. We previously reported the algorithms used to perform this fitting (Cotterell et al., 2015a, b; Preston and Reid, 2015). For all hygroscopic response measurements reported in this work, the RI varies with the particle size. Therefore, we parameterise $n_{\lambda}$ in terms of particle radius using the expression

$n_{\lambda}=n_{\lambda, 0}+\frac{n_{\lambda, 1}}{a^{3}}+\frac{n_{\lambda, 2}}{a^{6}}$,

in which $a$ is the particle radius, $n_{\lambda, 1}$ and $n_{\lambda, 2}$ are fitting parameters, and $n_{\lambda, 0}$ is the real RI of pure water at wavelength $\lambda$. This latter term is known precisely from bulk measurements and we use the data of Daimon and Masumura for water at $T=24{ }^{\circ} \mathrm{C}$ (Daimon and Masumura, 2007). Specifically, we use $n_{405,0}=1.343, n_{473,0}=1.338, n_{532,0}=1.335$, $n_{633,0}=1.332$ and $n_{650,0}=1.331$.

\section{Measuring $\sigma_{\text {ext }}$ for a single particle}

Once a single aerosol particle is optically trapped, the particle position is optimised to obtain a minimum in the measured RDT, corresponding to the particle being located at the centre of the ring-down beam. The position is varied in both transverse directions to the CRD beam, in the vertical direction by changing the laser power and in the horizontal direction by scrolling the translation stage on which the trapping cell is mounted. When the particle is centred in the CRD beam, a computer-controlled laser feedback is initiated to maintain a constant particle height over the duration of the measurement and values for $\tau$ are collected. After measurements have been made on the particle, the empty-cavity RDT, $\tau_{0}$, is recorded over several minutes. From knowledge of $\tau$ and $\tau_{0}, \sigma_{\text {ext }}$ is calculated using

$\sigma_{\mathrm{ext}}=\frac{L \pi w^{2}}{2 c}\left(\frac{1}{\tau}-\frac{1}{\tau_{0}}\right)$,

in which $L$ is the separation distance between the two cavity mirrors, $c$ is the speed of light and $w$ is the focal beam waist of the intra-cavity ring-down beam, which is either calculated using Gaussian optics (Kogelnik and Li, 1966) or is treated as a variable parameter when fitting the $\sigma_{\text {ext }}$ data to the prediction of a light-scattering model. We use the latter method for determining $w$ and have previously demonstrated that the fitted $w$ value agrees with the predictions of Gaussian optics (Cotterell et al., 2015b; Mason et al., 2014, 2015)

\subsection{Computational analysis of $\sigma_{\text {ext }}$ data}

Mie theory assumes that a travelling plane wave illuminates a homogeneous spherical particle. However, the field inside the optical cavity is a standing wave and not a travelling wave, with the extinction of light by aerosol varying for different phases of the standing wave (Mason et al., 2014; Miller and Orr-Ewing, 2007). The two cases of a particle centred at a standing wave node or antinode provide limiting values for $\sigma_{\text {ext }}$. A confined particle undergoes Brownian motion within the BB core over distances of micrometres, allowing the particle to sample standing-wave nodes, antinodes and intermediary phases. Therefore, the standing wave leads to a broadening in the measured $\sigma_{\text {ext }}$, with the limits in the recorded data corresponding to the particle located at either a node or antinode. To fit our measured $\sigma_{\text {ext }}$ vs. radius data, we use the cavity standing wave generalised Lorenz-Mie theory (CSWGLMT) equations that we have derived previously to calculate $\sigma_{\text {ext }}$ for the limiting cases of a node- and antinodecentred particle (Cotterell et al., 2016). These calculations provide a CSW-GLMT envelope, within which all the measured data are expected to lie (in the absence of experimental noise) for the best-fit simulation. A residual function, $R$, is defined by Eq. (4), in which the $\sigma_{\text {ext }, j}$ points included in the summation are only those with measured values that reside outside the simulated $\sigma_{\text {sim }}$ envelope and $\sigma_{\text {sim }, j}$ is the closer of the node- or antinode-centred simulation values at the given radius.

$R=\frac{1}{J} \sum_{j=1}^{J} \frac{\left|\sigma_{\mathrm{ext}, j}-\sigma_{\mathrm{sim}, j}\right|}{\rho_{j}}$

The density of the measured $\sigma_{\text {ext }}$ data points within a $1 \mathrm{~nm}$ range of the particle radius, $\rho_{j}$, is used as a weighting factor and prevents biasing of the fit to regions where the measured number of data points is high in the radius domain. The RI is varied to fit CSW-GLMT to the $\sigma_{\text {ext }}$ data, with the RI parameterised by Eq. (2) in terms of particle radius. The value of $R$ was minimised by varying the parameters $n_{\lambda, 1}$ and $n_{\lambda, 2}$, in addition to varying the beam waist, $w$. The $n_{\lambda, 1}$ and $n_{\lambda, 2}$ values that correspond to the minimum in $R$ define the best-fit refractive index. For the $1-2 \mu \mathrm{m}$ radius particles studied using either a 405 or $532 \mathrm{~nm} \mathrm{SP-CRDS}, n_{\lambda, 1}$ was typically varied over a range of 0 to $1 \times 10^{8} \mathrm{~nm}^{3}$ in steps of $1 \times 10^{6} \mathrm{~nm}^{3}$, while $n_{\lambda, 2}$ was varied over a range of $-1 \times 10^{18}$ to $0 \mathrm{~nm}^{6}$ in steps of $1 \times 10^{16}$. A grid search was used to vary the three parameters $n_{\lambda, 1}, n_{\lambda, 2}$ and $w$ such that all points in the threedimensional search space were sampled.

\section{SP-CRDS measurements for hygroscopic inorganic aerosol particles}

Single aqueous aerosol droplets containing one of the inorganic solutes of interest $\left(\mathrm{NaCl}, \mathrm{NaNO}_{3},\left(\mathrm{NH}_{4}\right)_{2} \mathrm{SO}_{4}\right.$, $\mathrm{NH}_{4} \mathrm{HSO}_{4}$ or $\left.\mathrm{Na}_{2} \mathrm{SO}_{4}\right)$ were optically trapped using the SPCRDS instruments at high ( 80-85\%) RH. Following nebulisation, the ambient RH was unsteady and thus no action was taken during a conditioning period of $\sim 10$ min until the $\mathrm{RH}$ had stabilised. The RH was subsequently lowered over 

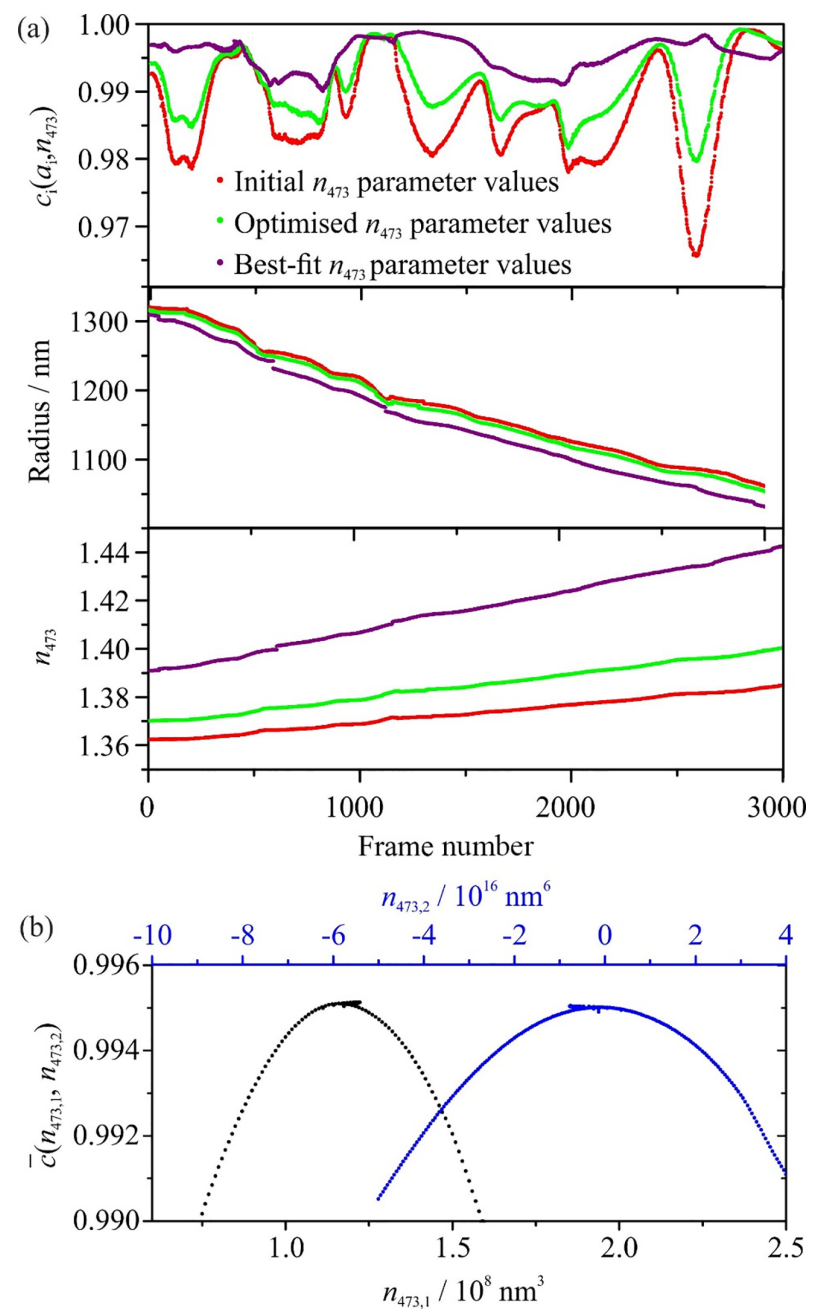

Figure 2. (a) The fitted radius, $n_{473}$, and correlation coefficient variation with frame number for an aqueous $\mathrm{NaNO}_{3}$ droplet. Red points correspond to initial $n_{473}$ parameter values, green points to further optimised values and purple points to the best-fit values. (b) The mean correlation coefficient, $\bar{c}\left(n_{473}\right)$, and the parameters $n_{473,1}$ and $n_{473,2}$ were varied.

time at a near-constant rate of $0.4-0.5 \%$ per minute, until the particle effloresced or the particle size was such that it was unstable and was ejected from the optical trap. While lowering the RH, $\tau$ and PFs were recorded at a rate of $\sim 10$ and $1 \mathrm{~s}^{-1}$, respectively. Repeat measurements ( $\sim 5$ droplets) were performed for all inorganic solutes of interest using both of the SP-CRDS instruments and, in the case of $405 \mathrm{~nm}$ SP-CRDS, using the $532 \mathrm{~nm} \mathrm{BB}$ for PF measurements. This work considers measurements of particles with mean particle radii $>1 \mu \mathrm{m}$ only, as we have previously found that $n_{\lambda}$ retrievals for hygroscopic particles in this size range are accurate to $<0.001$, while this accuracy degrades significantly for smaller particles (Cotterell et al., 2016).

\subsection{Radius and refractive index retrieval from recorded phase functions}

Prior to analysis of the $\sigma_{\text {ext }}$ data, the particle radius and $n_{\lambda}$ at the PF acquisition wavelength were determined from fitting the PFs to Mie theory (see Sect. 2.1). We refer the reader to Fig. 1 in Cotterell et al. (2015a) and Fig. 4 in Carruthers et al. (2012) for examples of raw PF images recorded using our instrumentation. As described previously (Cotterell et al., 2015a, b), a mean Pearson correlation coefficient $\bar{c}\left(n_{\lambda}\right)$ is used to quantify the level of agreement between the measured PF data set and the set of best-fit Mie theory simulations, with $\bar{c}\left(n_{\lambda}\right)=1$ corresponding to perfect agreement and lower values of $\bar{c}\left(n_{\lambda}\right)$ indicative of a poorer fit. The entire PF data set is made up of typically $5000 \mathrm{PFs}$, each with a corresponding Pearson correlation coefficient value, $c\left(n_{\lambda}\right)$, which each contribute to the overall mean Pearson correlation coefficient value, $\bar{c}\left(n_{\lambda}\right)$. Figure $2 \mathrm{a}$ shows the variation in the fitted Pearson correlation coefficient $c\left(n_{473}\right)$, radius and $n_{473}$ with time (labelled as frame number, with $\mathrm{PF}$ frame acquisition rate of $1 \mathrm{~s}^{-1}$ ) when fitting $473 \mathrm{~nm}$ PFs from a measurement on an aqueous $\mathrm{NaNO}_{3}$ particle. Data are shown for the initial $n_{473}$ fitting parameter values $\left(n_{473,1}=5.6 \times 10^{7} \mathrm{~nm}^{3}, n_{473,2}=0.0 \mathrm{~nm}^{6}\right)$, for further optimised values $\left(n_{473,1}=7.3 \times 10^{7} \mathrm{~nm}^{3}, n_{473,2}=0.0 \mathrm{~nm}^{6}\right)$ and for the best-fit parameter values $\left(n_{473,1}=1.221 \times 10^{8} \mathrm{~nm}^{3}\right.$, $\left.n_{473,2}=-7.585 \times 10^{15} \mathrm{~nm}^{6}\right)$. Figure $2 \mathrm{~b}$ shows how the mean correlation coefficient $\bar{c}\left(n_{473}\right)$ varies with $n_{473,1}$ and $n_{473,2}$ on their initial search cycles. Further data points that correspond to refined grid-search cycles can be seen. There are clear maxima in $\bar{c}\left(n_{473}\right)$ as $n_{473,1}$ and $n_{473,2}$ are varied, with the maximum having a value of $\bar{c}\left(n_{473}\right)=0.9951$.

For the SP-CRDS measurements reported in this work, each hygroscopic response measurement has a $\bar{c}\left(n_{\lambda}\right)$ value associated with the fitting of the PFs. When using 473 (or $633) \mathrm{nm}$ probe laser beam illumination, values of $\bar{c}\left(n_{473}\right)$ (and $\left.\bar{c}\left(n_{633}\right)\right)$ averaged over all hygroscopic response measurements performed at the respective wavelengths were $0.993 \pm 0.003$ (and $0.99646 \pm 0.00004$ ), in which the errors represent 1 standard deviation in the $\bar{c}\left(n_{\lambda}\right)$. We also collected PFs of the elastically scattered light from the BB illumination, which resulted in lower values of $\bar{c}\left(n_{\lambda}\right)$ compared to illumination from a Gaussian probe beam; the corresponding $\bar{c}\left(n_{532}\right)$ value from BB illumination was $0.985 \pm 0.008$. This lower $\bar{c}\left(n_{\lambda}\right)$ value indicates that the use of PFs from illumination with the BB light (core of diameter $\sim 5.5 \mu \mathrm{m}$ ) is detrimental to radius and $n_{532}$ determination, with more accurate determinations arising when analysing the PFs from Gaussian illumination at 473 and $633 \mathrm{~nm}$. The component wave vectors constituting the $\mathrm{BB}$ make large angles with respect to the optical propagation axis, while Mie theory assumes that a plane wave illuminates a spherical particle. The 473 and $633 \mathrm{~nm}$ probe beams have Gaussian profiles with spot diameters estimated to be $\sim 30$ and $\sim 15 \mu \mathrm{m}$, respectively, at the particle trapping location and are more representative of 


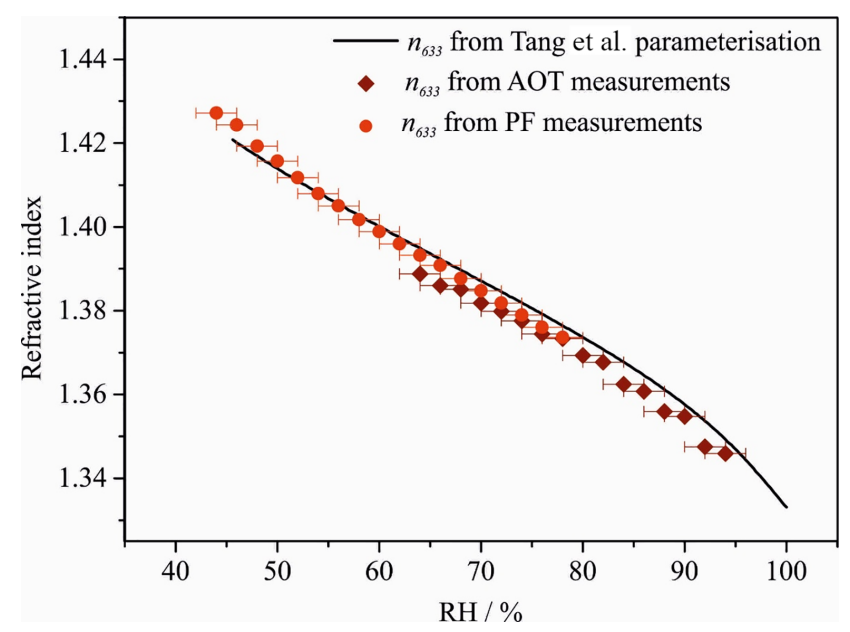

Figure 3. Comparison of the RH-dependant parameterisation of $n_{633}$ reported by Tang et al. (1997) and Tang and Munkelwitz (1994) for aqueous $\mathrm{NaCl}$ to $n_{633}$ measured from $633 \mathrm{~nm}$ Gaussian-illuminated PFs and Raman spectroscopy from aerosol optical tweezer measurements. The error bars correspond to uncertainties associated with RH measurements.

plane wave illumination compared to that provided by the trapping BBs. Section 3.4 further analyses the consequential errors in the derived particle size and $n_{532}$ due to BB illumination.

\subsection{Comparison of refractive index retrieval methods}

The $633 \mathrm{~nm}$ probe beam was used for PF illumination to provide a comparison of the refractive index retrieval accuracy from PF imaging with AOT measurements (using Eq. 5) and measurements by Tang et al. (Tang et al., 1997; Tang and Munkelwitz, 1994) for the aqueous $\mathrm{NaCl}$ system only. For the final set of data presented in Sect. 4, the parameterisation by Tang et al. is used to represent $n_{633}$ for all compounds. In addition, for the retrieval of RIs from the $405 \mathrm{~nm}$ SP-CRDS system, all droplet radii were retrieved from PFs using BB illumination at $532 \mathrm{~nm}$ rather than at $633 \mathrm{~nm}$ (Tang et al., 1997; Tang and Munkelwitz, 1994).

The refractive index from AOT measurements is retrieved from Raman spectroscopy measured at $650 \mathrm{~nm}$. The fitting of the Raman spectra yields not only $n_{650}$ but also dispersion terms, $m_{1}$ and $m_{2}$, which allow the refractive index to be calculated at alternative wavelengths:

$n=n_{0}+m_{1}\left(v-v_{0}\right)+m_{2}\left(v-v_{0}\right)^{2}$.

Here, $n$ is the refractive index at the desired wavelength, $n_{0}$ is the refractive index at the measured wavelength $\left(n_{650}\right.$ in this case), $v$ is the wave number of the desired wavelength and $v_{0}$ is the wave number at the measurement illumination wavelength.

Figure 3 shows $n_{633}$ for an aqueous sodium chloride particle retrieved from AOT measurements and the average of
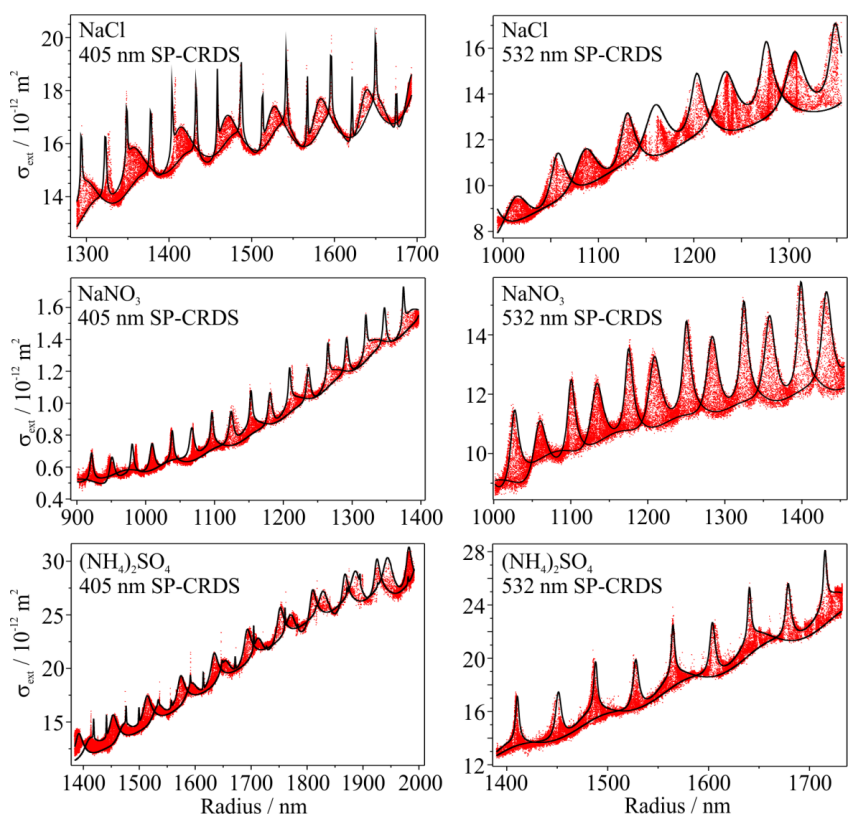

Figure 4. Representative SP-CRDS measurements of $\sigma_{\text {ext }}$ (red points) and best-fit CSW Mie envelopes (black lines) for aqueous aerosol particles containing the inorganic solutes $\mathrm{NaCl}, \mathrm{NaNO}_{3}$, and $\left(\mathrm{NH}_{4}\right)_{2} \mathrm{SO}_{4}$. The measured $\sigma_{\text {ext }}$ values were collected using either $405 \mathrm{~nm}$ (left column) or $532 \mathrm{~nm}$ (right column) SP-CRDS.

three measurements from PFs measured on the $405 \mathrm{~nm}$ SPCRDS instrument, with good agreement between the techniques. Furthermore, $n_{633}$ values from both techniques are consistent with the parameterisation of $n_{633}$ from Tang et al., within the RH uncertainty indicated corresponding to $\pm 2 \%$ for AOT and PF measurements. Although the RH ranges of the new measurements do not perfectly match for the limited number of measurements compared here, the consistency between the new measurements and the previous parameterisation provided by Tang et al. is sufficient for validating the measurement approaches. Hargreaves et al. compare EDB and optical tweezer measurements of aqueous $\mathrm{NaCl}$ to the Tang parameterisation, reporting good agreement to Tang et al. at high RH $(>70 \pm 0.2 \%)$ with increasing divergence at low $\mathrm{RH}(45+5 \%)$, at which the error in $\mathrm{RH}$ represents the equivalent offset in $\mathrm{RH}$ required to bring the different measurements into agreement (Hargreaves et al., 2010). For $\left(\mathrm{NH}_{4}\right)_{2} \mathrm{SO}_{4}$, Tang et al. (Tang and Munkelwitz, 1994) acknowledged that although their measurements agreed with those of Richardson and Spann (Richardson and Spann, 1984) at high RH, there was divergence from measurements by Cohen and co-workers by an RH equivalent of 4-5\% (Cohen et al., 1987). Despite this, the $n_{633}$ measurements from three different techniques show good agreement within the uncertainty in $\mathrm{RH}$, reinforcing the premise that the different techniques offer an accurate means of retrieving $n_{\lambda}$ as a function of RH and are compatible for combining in the RI parameterisation presented in Sect. 4. This com- 
parison also demonstrates that PF measurements can be used to accurately retrieve particle radius and RI. It should also be noted that the AOT measurements are centred at a wavelength of $650 \mathrm{~nm}$ and the values reported in the figure are the corrected values for $633 \mathrm{~nm}$. Over this wavelength range, the RI change from 650 to $633 \mathrm{~nm}$ is $\sim-0.0017$ at a typical RH of $80 \%$.

\subsection{Extinction cross section measurements}

Once the time evolution in particle radius was determined from the PFs, the measured $\sigma_{\text {ext }}$ data were compared to CSW-GLMT calculations using the procedure described in Sect. 2.2. Figure 4 shows example $\sigma_{\text {ext }}$ data sets measured using either 405 or $532 \mathrm{~nm}$ SP-CRDS and the best-fit CSW Mie envelopes. For the example data presented in this figure, the particle radii for measurements using $405 \mathrm{~nm}$ SP-CRDS are from fitting the $532 \mathrm{~nm}$ PFs (i.e. using BB illumination) and for $532 \mathrm{~nm}$ SP-CRDS the radii are from fitting $473 \mathrm{~nm}$ PFs (from the probe beam illumination). The $\sigma_{\text {ext }}$ data sets measured using $405 \mathrm{~nm}$ SP-CRDS have a higher number of resonance features compared to the data sets measured using $532 \mathrm{~nm}$ SP-CRDS, even though the particles evaporated over similar radius ranges, owing to the $1 / \lambda$ dependence of the particle size parameter. The higher number of resonance features in the $\sigma_{\text {ext }}$ data at lower wavelengths is expected to facilitate higher precision determinations of $n_{\lambda}$.

\subsection{Multi-wavelength determinations of the refractive index}

The precision in $n_{\lambda}$ retrievals from $\sigma_{\text {ext }}$ and PF data was tested by repeat SP-CRDS measurements on different aqueous droplets containing the inorganic solutes of interest. The retrieved $n_{\lambda}$ values were represented as a function of the RH, as measured by a calibrated capacitance probe located $\sim 1 \mathrm{~cm}$ from the droplet trapping location. The $n_{\lambda}$ data were binned in $2 \% \mathrm{RH}$ intervals because the capacitance probe RH measurements have a standard error of $\pm 2 \%$. Repeat measurements of $n_{\lambda}$ were then averaged for each RH bin and a standard deviation, $s_{\lambda}(\mathrm{RH})$, was calculated. The values of $n_{405}$ and $n_{473}$ were retrieved from fitting the $\sigma_{\text {ext }}(\lambda=405 \mathrm{~nm})$ and $\operatorname{PF}(\lambda=473 \mathrm{~nm})$ data, respectively. This section presents the average $n_{532}$ calculated from $\sigma_{\text {ext }}(\lambda=532 \mathrm{~nm})$ data only and neglects the $n_{532}$ value retrieved from PF analysis, assuming that the RI retrieval using $\sigma_{\text {ext }}$ data is more precise than using PFs from BB scattering. Section 3.5 presents a thorough analysis of the impact of BB illumination on $n_{532}$ precision. Table 1 reports the number of particles studied for each inorganic species using either 405 or $532 \mathrm{~nm}$ SP-CRDS. Data are shown for $405 \mathrm{~nm}$ SP-CRDS measurements using the BB probe beam for PF collection.

Figure 5 summarises the average retrieved RIs $\left(n_{405}, n_{473}\right.$ and $n_{532}$ ) binned in $2 \% \mathrm{RH}$ intervals for each of the inorganic solutes of interest. Also shown are the $n_{633}$ variations
Table 1. Information relating to the precision of $n_{\lambda}$ measured from SP-CRDS for aqueous $\mathrm{NaCl}, \mathrm{NaNO}_{3},\left(\mathrm{NH}_{4}\right)_{2} \mathrm{SO}_{4}, \mathrm{NH}_{4} \mathrm{HSO}_{4}$ and $\mathrm{Na}_{2} \mathrm{SO}_{4}$ droplets. $N$ is the number of data sets available for phase function and extinction cross section $\left(\sigma_{\text {ext }}\right)$ analysis from either $405 \mathrm{~nm}$ or $532 \mathrm{~nm}$ SP-CRDS. The mean standard deviation in the retrieved $n_{\lambda}, \overline{s\left(n_{\lambda}\right)}$ is reported for both extinction cross section and phase function (PF) measurements.

\begin{tabular}{|c|c|c|c|c|c|c|}
\hline & \multicolumn{3}{|c|}{$\begin{array}{l}405 \mathrm{~nm} \text { SP-CRDS } \\
\text { (using } 532 \mathrm{~nm} \text { PFs) }\end{array}$} & \multicolumn{3}{|c|}{$532 \mathrm{~nm}$ SP-CRDS } \\
\hline & $N$ & $\begin{array}{r}\overline{s\left(n_{532}\right)} \\
(\mathrm{PFs})\end{array}$ & $\begin{array}{r}\overline{s\left(n_{405}\right)} \\
\left(\sigma_{\text {ext }}\right)\end{array}$ & $N$ & $\begin{array}{r}\overline{s\left(n_{473}\right)} \\
\quad(\mathrm{PFs})\end{array}$ & $\begin{array}{r}s\left(n_{532}\right) \\
\left(\sigma_{\text {ext }}\right)\end{array}$ \\
\hline $\mathrm{NaCl}$ & 5 & 0.0088 & 0.0044 & 7 & 0.0038 & 0.0030 \\
\hline $\mathrm{NaNO}_{3}$ & 7 & 0.0053 & 0.0034 & 5 & 0.0028 & 0.0015 \\
\hline$\left(\mathrm{NH}_{4}\right)_{2} \mathrm{SO}_{4}$ & 4 & 0.0086 & 0.0041 & 9 & 0.0036 & 0.0027 \\
\hline $\mathrm{NH}_{4} \mathrm{HSO}_{4}$ & 3 & 0.0130 & 0.0095 & 4 & 0.0054 & 0.0025 \\
\hline $\mathrm{Na}_{2} \mathrm{SO}_{4}$ & - & - & - & 9 & 0.0072 & 0.0062 \\
\hline
\end{tabular}

reported by Tang et al. (Tang et al., 1997; Tang and Munkelwitz, 1994) and values for $n_{589}$ reported in the CRC Handbook of Chemistry and Physics (Haynes, 2015). The CRC handbook reports measured values of $n_{589}$ in terms of mass fraction of solute. Therefore, the E-AIM model was used to relate solute mass fraction to water activity (AIM, 2017; Clegg et al., 1998). Furthermore, the CRC handbook does not report RI values for $\mathrm{NH}_{4} \mathrm{HSO}_{4}$ and the $n_{589}$ values plotted in Figs. $5 \mathrm{~d}$ and $8 \mathrm{~d}$ were taken from bulk solution measurements using a refractometer (Misco, Palm Abbe).

In general, Fig. 5 shows that $n_{\lambda}$ increases towards shorter wavelengths, as expected given the chromatic dispersion behaviour of typical materials. Furthermore, the optical dispersion increases as the RH decreases and the solute becomes more concentrated within the aqueous droplets. The increasing separation between the measured RH-dependent $n_{\lambda}$ values for progressively shorter wavelengths indicates the increasing influence of optical dispersion. At higher RH values (>80\%), the measured values of $n_{405}, n_{473}$, and $n_{532}$ approach one another and, in the case of $\mathrm{NaNO}_{3}$, the values of $n_{405}$ become lower than the measured $n_{473}$ and $n_{532}$ values. The RI values are expected to converge as the RH tends to $100 \%$ (the RI variation with wavelength in the visible spectrum is low for pure water) (Daimon and Masumura, 2007), but this crossing is likely to derive from calibration errors in the RH probes, noting that the set of $\left\{n_{405}, n_{532}\right\}$ and $\left\{n_{473}\right.$, $\left.n_{532}\right\}$ measurements are made using different SP-CRDS instruments.

The $n_{589}$ bulk measurements are limited by the solubility of each solute, which constrains measurements to high water activity (RH) values. As expected, in all cases, the bulk $n_{589}$ literature data lie close to, or match, the $n_{633}$ values. Small deviations of $n_{589}$ from $n_{633}(>0.003)$ for $\mathrm{NH}_{4} \mathrm{HSO}_{4}$ and $\mathrm{NaNO}_{3}$ can be observed in Fig. 5. While the RH values for the $n_{589}$ data are calculated from measured solute mass fraction data (which are expected to be accurate to $<1 \%$ ) us- 

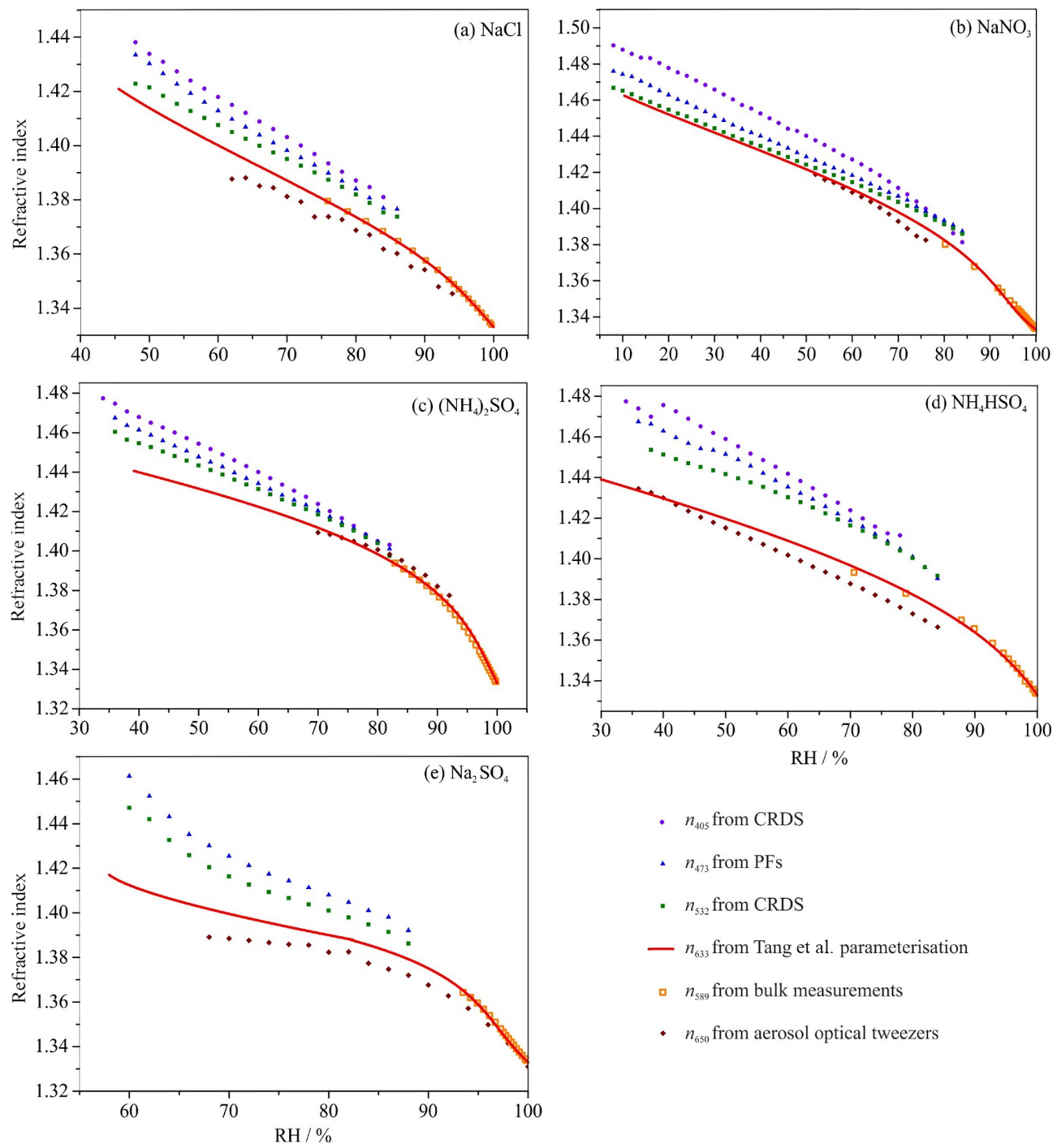

- $n_{405}$ from CRDS

- $n_{473}$ from PFs

- $n_{532}$ from CRDS

- $n_{633}$ from Tang et al. parameterisation

- $n_{\mathrm{sg} 9}$ from bulk measurements

- $n_{650}$ from aerosol optical tweezers

Figure 5. The average $n_{\lambda}$ variations with RH for aqueous droplets containing the inorganic solutes of interest. The uncertainties in $n_{\lambda}$ have not been included here for clarity; they are listed in Table 1.

ing the E-AIM model (AIM, 2017; Clegg et al., 1998), the RH measurements associated with the $n_{633}$ parameterisation are expected to be more uncertain, up to $\pm 5 \%$ at $\mathrm{RH}<45 \%$, as discussed in Sect. 3.2. Therefore, it is reasonable to see deviations in the order of the data points at high $\mathrm{RH}$ in line with the uncertainty associated with the RH measurements.

In most cases the $n_{650}$ data lie below the data measured at shorter wavelengths, which follows the expected trend of chromatic dispersion. In the cases of $\mathrm{NaNO}_{3},\left(\mathrm{NH}_{4}\right)_{2} \mathrm{SO}_{4}$ and $\mathrm{NH}_{4} \mathrm{HSO}_{4}$, the $n_{650}$ values cross the $n_{633}$ values, which is attributed to uncertainties in RH measurements from both the AOT and Tang parameterisation of \pm 2 and $\sim \pm 5 \%$, respectively (Tang and Munkelwitz, 1994).

\subsection{Precision in refractive index determined using SP-CRDS}

The precision in the RI values determined using SP-CRDS can be quantified by the standard deviation in $n_{\lambda}$ within a $2 \%$ RH interval. For ease of reading, the plots in Fig. 5 do not show error bars representing this standard deviation. Instead, the means of the standard deviation values over all the RH bins are calculated and denoted, $\overline{s\left(n_{\lambda}\right)}$. Table 1 presents the $\overline{s\left(n_{\lambda}\right)}$ values for each inorganic solute of interest as measured on each of the SP-CRDS instruments. In all cases, the retrieved RI from fitting $\sigma_{\text {ext }}$ data is more precise than from the corresponding $\mathrm{PF}$ analysis.

For measurements performed using the $532 \mathrm{~nm}$ SP-CRDS instrument, the precision of $n_{473}$ and $n_{532}$ measurements (from PFs and CRDS, respectively) was generally high, indi- 

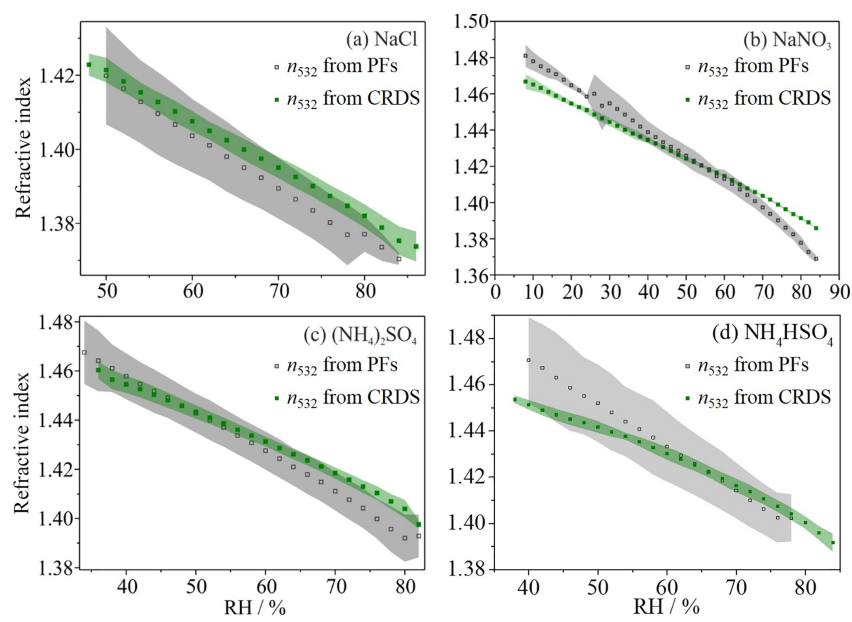

Figure 6. Comparison of $n_{532}$ values determined from either PFs recorded using BB illumination or $\sigma_{\text {ext }}$ data using $532 \mathrm{~nm}$ SPCRDS. The shaded envelopes represent 1 standard deviation in the measurements.

cated by the majority of $\overline{s\left(n_{473}\right)}$ values $<0.004$ and $\overline{s\left(n_{532}\right)}$ values $<0.003$ in Table 1 . The only exception was $\mathrm{Na}_{2} \mathrm{SO}_{4}$ for which the standard deviations for the measurements are larger, $\overline{s\left(n_{473}\right)} \sim 0.007$ and $\overline{s\left(n_{532}\right)} \sim 0.006 . \mathrm{Na}_{2} \mathrm{SO}_{4}$ effloresces at relatively high $\mathrm{RH}(\sim 60 \%)$, thereby limiting the radius range accessed during drying. This reduces the extent of the resonant structure observed, which provides the greatest constraint on RI retrievals and limits the precision of the $n_{\lambda}$ determination. The measurements from the $405 \mathrm{~nm}$ SPCRDS instrument are not as precise as those performed on the $532 \mathrm{~nm}$ SP-CRDS instrument owing to the collection of PFs from BB illumination, in which $\overline{s\left(n_{532}\right)}$ and $\overline{s\left(n_{473}\right)}$ values are in the range of 0.005-0.013 and 0.003-0.007, respectively. The $\overline{s\left(n_{532}\right)}$ values from (BB-illuminated) PFs are significantly higher than $\overline{s\left(n_{405}\right)}$ retrieved from CRDS; the majority of solutes (except $\mathrm{NH}_{4} \mathrm{HSO}_{4}$ ) have $\overline{s\left(n_{405}\right)}<0.0045$. The $\mathrm{NH}_{4} \mathrm{HSO}_{4} \overline{s\left(n_{532}\right)}$ values are particularly high, which influences the retrieved $\overline{s\left(n_{405}\right)}$ since information relating to the geometric size of the particle from $\mathrm{PF}$ data is required in the $\sigma_{\text {ext }}$ data fitting procedure. The $\mathrm{NH}_{4} \mathrm{HSO}_{4}$ values of $\overline{s\left(n_{532}\right)}=0.013$ and $\overline{s\left(n_{405}\right)} \sim 0.01$ emphasise the recommendation to use a probe Gaussian beam for PF illumination to improve precision in both $n_{\lambda}$ from PFs and $n_{\lambda}$ from CRDS in the long term.

We now provide further evidence that reliable RI retrievals from fitting Mie theory to PFs cannot be performed when the illuminating light field is a focussed BB. Figure 6 compares $n_{532}$ values retrieved from CRDS and BB-illuminated PFs. Measurements using $405 \mathrm{~nm}$ SP-CRDS were performed for aqueous $\mathrm{Na}_{2} \mathrm{SO}_{4}$ but the non-linear dependence of $n_{\lambda}$ on $\mathrm{RH}$ and possible impurities in the sample prevented fitting the $532 \mathrm{~nm}$ PFs to Mie theory (and therefore $405 \mathrm{~nm} \sigma_{\text {ext }}$ measurements to CSW-GLMT). Therefore, $\mathrm{Na}_{2} \mathrm{SO}_{4} n_{405}$ measurements are not discussed further. For each inorganic so-
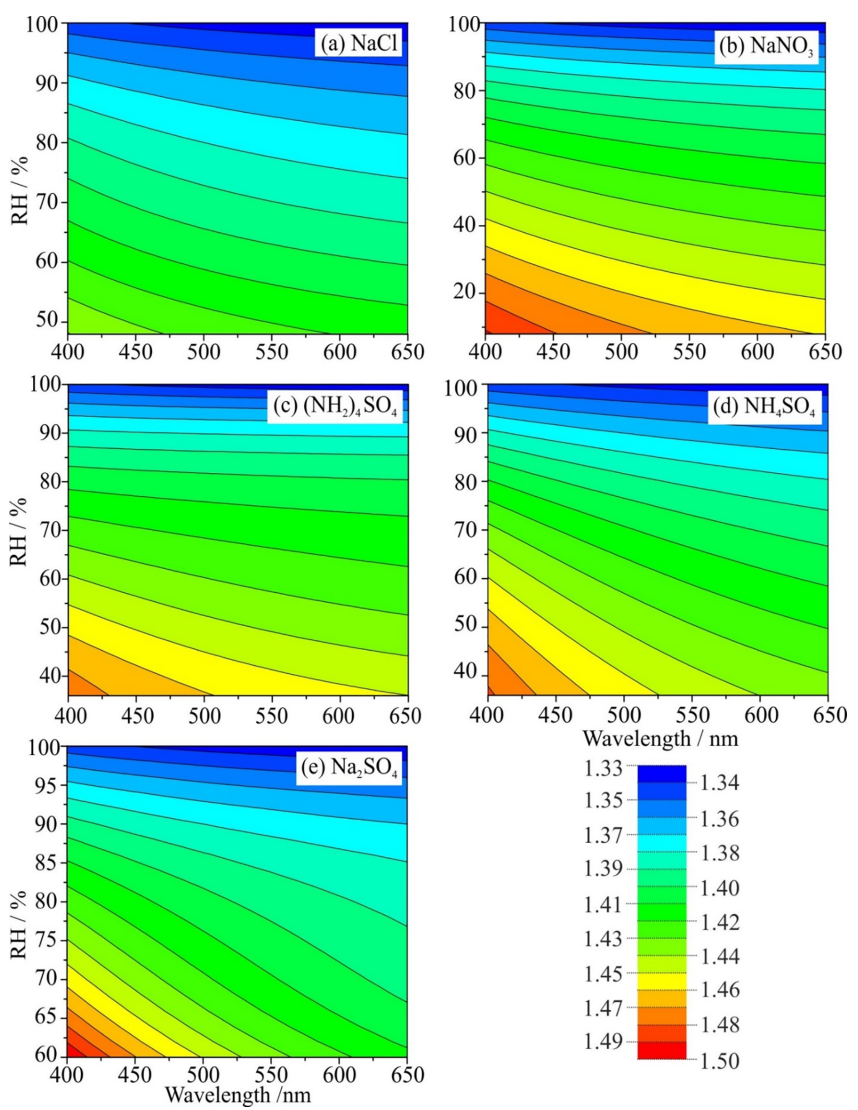

Figure 7. Contour plots representing the parameterisation of RI as a function of both wavelength and $\mathrm{RH}$ for aqueous aerosol particles containing the inorganic solutes of interest.

lute studied, the precision in the $n_{532}$ values retrieved from the PFs is poorer than retrievals from $\sigma_{\text {ext }}$ data, indicated by PF $\overline{s\left(n_{532}\right)}$ values being approximately twice the equivalent $\overline{s\left(n_{532}\right)} \sigma_{\text {ext }}$ data, as indicated in Table 1 . Moreover, the slopes of the RI vs. RH plots in Fig. 6a-d are steeper for the PF-retrieved, compared to the $\sigma_{\text {ext }}$-retrieved, $n_{532}$ data. The PF-retrieved $n_{532}$ for $\mathrm{NH}_{4} \mathrm{HSO}_{4}$ (Fig. 6d) has both a significantly larger standard deviation and divergence from $n_{532} \sigma_{\text {ext }}$ data. The propagation of this uncertainty in PFretrieved RI (and particle size) into the $\sigma_{\text {ext }}$-retrieved $n_{405}$ values is evident, with $\overline{s\left(n_{405}\right)}=0.0095$. Although the precisions of $n_{532}$ and radius retrievals are compromised when fitting PFs using BB illumination, the corresponding $\overline{s\left(n_{405}\right)}$ from fitting $\sigma_{\text {ext }}$ data is, on the whole, close to $\sigma_{\text {ext-retrieved }}$ $\overline{s\left(n_{532}\right)}$ from probe beam PF illumination (with the exception of $\mathrm{NH}_{4} \mathrm{HSO}_{4}$ ), with values in the range of $0.003-0.005$ (Table 1). Furthermore, the $\overline{s\left(n_{405}\right)}$ values indicate a precision better than twice that of the corresponding $\overline{s\left(n_{532}\right)}$ from fitting PFs.

All $\overline{s\left(n_{\lambda}\right)}$ values encompass contributions from both variation in $n_{\lambda}$ and, more significantly, from uncertainties in measuring the RH. Indeed, we have recently reported that the $n_{\lambda}$ retrieval accuracy from fitting $532 \mathrm{~nm}$ SP-CRDS $\sigma_{\text {ext }}$ data is 
Table 2. Summary of the best-fit parameters to describe the RI variation with both wavelength and RH for the inorganic solutes of interest. The parameters and function forms are defined in Eqs. (7)-(9). $N$ is the total number of measured and literature data points (shown in Fig. 5) to which the parameterisation was fitted. $\overline{|\Delta n|}$ is the mean absolute difference between the best-fit Cauchy model and the measured and literature data.

\begin{tabular}{lrrrrr}
\hline & $\mathrm{NaCl}$ & $\mathrm{NaNO}_{3}$ & $\left(\mathrm{NH}_{4}\right)_{2} \mathrm{SO}_{4}$ & $\mathrm{NH}_{4} \mathrm{HSO}_{4}$ & $\mathrm{Na}_{2} \mathrm{SO}_{4}$ \\
\hline$n_{0,0}$ & 1.3495 & 1.4767 & 1.3764 & 1.4649 & 2.3810 \\
$n_{0,1} / 10^{-2}$ & 0.8770 & -0.0761 & 0.8552 & 0.0690 & -3.2494 \\
$n_{0,2} / 10^{-4}$ & -2.6190 & -0.1451 & -2.7632 & -0.4877 & 3.3485 \\
$n_{0,3} / 10^{-6}$ & 2.8864 & 0.2941 & 3.3769 & 0.6234 & -0.5428 \\
$n_{0,4} / 10^{-8}$ & -1.1586 & -0.2147 & -1.5096 & -0.3336 & -0.6018 \\
$n_{1,0} / 10^{-2}$ & 7.0981 & 3.1219 & -5.7022 & 3.8202 & 34.8882 \\
$n_{1,1} / 10^{-4}$ & -21.7961 & -1.8033 & 46.6467 & 4.1621 & -61.1350 \\
$n_{1,2} / 10^{-6}$ & 31.1422 & -1.4789 & -82.4706 & -6.4225 & 27.6052 \\
$n_{1,3} / 10^{-8}$ & -15.5951 & 1.3676 & 42.4736 & -0.5106 & 0.0000 \\
$N$ & 121 & 190 & 130 & 164 & 86 \\
$\overline{|\Delta n|}$ & 0.0020 & 0.0016 & 0.0018 & 0.0044 & 0.0027 \\
\hline
\end{tabular}

$< \pm 0.001$ for the size range of hygroscopic response measurements performed in this paper $(>1 \mu \mathrm{m})$, although our previous analysis neglected the influence of sample impurities on the retrieved $n_{\lambda}$ (Cotterell et al., 2016). As an example, $\overline{s\left(n_{473)}\right)}$ and $\overline{s\left(n_{532}\right)}$ take respective values of 0.0028 and 0.0015 for the measurements of $\mathrm{NaNO}_{3}$. The uncertainty of $\pm 2 \%$ in the recorded $\mathrm{RH}$ probe value is calculated to contribute uncertainties of 0.0023 and 0.0021 to $\overline{s\left(n_{473}\right)}$ and $\overline{s\left(n_{532}\right)}$, respectively. Therefore, any errors in particle sizing from $473 \mathrm{~nm}$ PFs and noise in the recorded $\tau$ data make only a small contribution to the $n_{\lambda}$ precision in the RH domain.

\section{Parameterising the refractive index with variation in wavelength and $R H$}

The plots in Fig. 5 contain all the information to characterise the RI in terms of both wavelength and RH. Here, we develop an RI model that accounts for variations in both wavelength and $\mathrm{RH}$, and this model is fitted to the data in Fig. 5 to parameterise $n(\lambda, \mathrm{RH})$. The Cauchy equation is an empirical relation describing the wavelength dependence in the RI and can be written as (David et al., 2016)

$n=n_{0}+\sum_{i=1}^{N} n_{i}\left[\left(\frac{\lambda_{0}}{\lambda}\right)^{2 i}-1\right]$,

in which $n_{0}$ is the RI at reference wavelength $\lambda_{0}$ and $n_{i}$ is the dispersion coefficient. In our model, we find that expansion of the summation in Eq. (6) to $i=1$ is required only when

$n=n_{0}+n_{1}\left[\left(\frac{\lambda_{0}}{\lambda}\right)^{2}-1\right]$.

To incorporate the RH dependence of the RI into Eq. (7), we note that $n_{0}$ and $n_{1}$ are expected to be smooth functions of RH and thus we parameterise $n_{0}$ and $n_{1}$ as polynomial functions of the water activity. In our Cauchy model, we use $\lambda_{0}=525 \mathrm{~nm}$ since this wavelength is at the centre of the wavelength range (405-650 nm) over which we have RI data available. The values for $n_{0}$ and $n_{1}$ are described by the following quartic and cubic polynomial equations, respectively, in terms of $a_{w}$ :

$$
\begin{aligned}
n_{0} & =n_{0,0}+n_{0,1}\left(100 a_{w}\right)+n_{0,2}\left(100 a_{w}\right)^{2} \\
& +n_{0,3}\left(100 a_{w}\right)^{3}+n_{0,4}\left(100 a_{w}\right)^{4} \\
n_{1} & =n_{1,0}+n_{1,1}\left(100 a_{w}\right)+n_{1,2}\left(100 a_{w}\right)^{2} \\
& +n_{1,3}\left(100 a_{w}\right)^{3} .
\end{aligned}
$$

The parameters $\left(n_{0, x}, \ldots\right)$ and $\left(n_{1, x}, \ldots\right)$ are fitted concurrently by performing a least squares fit to Eq. (7) by minimising the residual between the measured and literature data $\left(n_{405}, n_{473}, n_{532}, n_{650}, n_{589}, n_{633}\right)$ and the $n_{\lambda}$ generated by the Cauchy model. The Microsoft Excel generalised reduced gradient non-linear engine is used to accomplish this fitting, constraining the modelled $n_{\lambda}$ to the value of pure water at RH $=100 \%$ (Daimon and Masumura, 2007). Figure 7 presents the results as contour plots for each inorganic solute of interest. These contour plots represent the most comprehensive description of RI for atmospherically relevant inorganic aerosol, fully characterising the RI variation with both visible wavelength and RH. The best-fit parameters for Eqs. (8) and (9) that describe these contour plots are summarised in Table 2.

Figure 8 compares the measured data points with the Cauchy model curves from the aforementioned global fitting procedure (i.e. using the relevant parameters in Table 2). This plot only shows data at $10 \% \mathrm{RH}$ intervals for simplicity. The total number of literature and measured data points, $N$, used in the fitting procedure are indicated for each solute in Table 2. The agreement between the Cauchy model and data at $\mathrm{RH}=100 \%$ highlights that the model is constrained to the RI of pure water. The error bars represent 

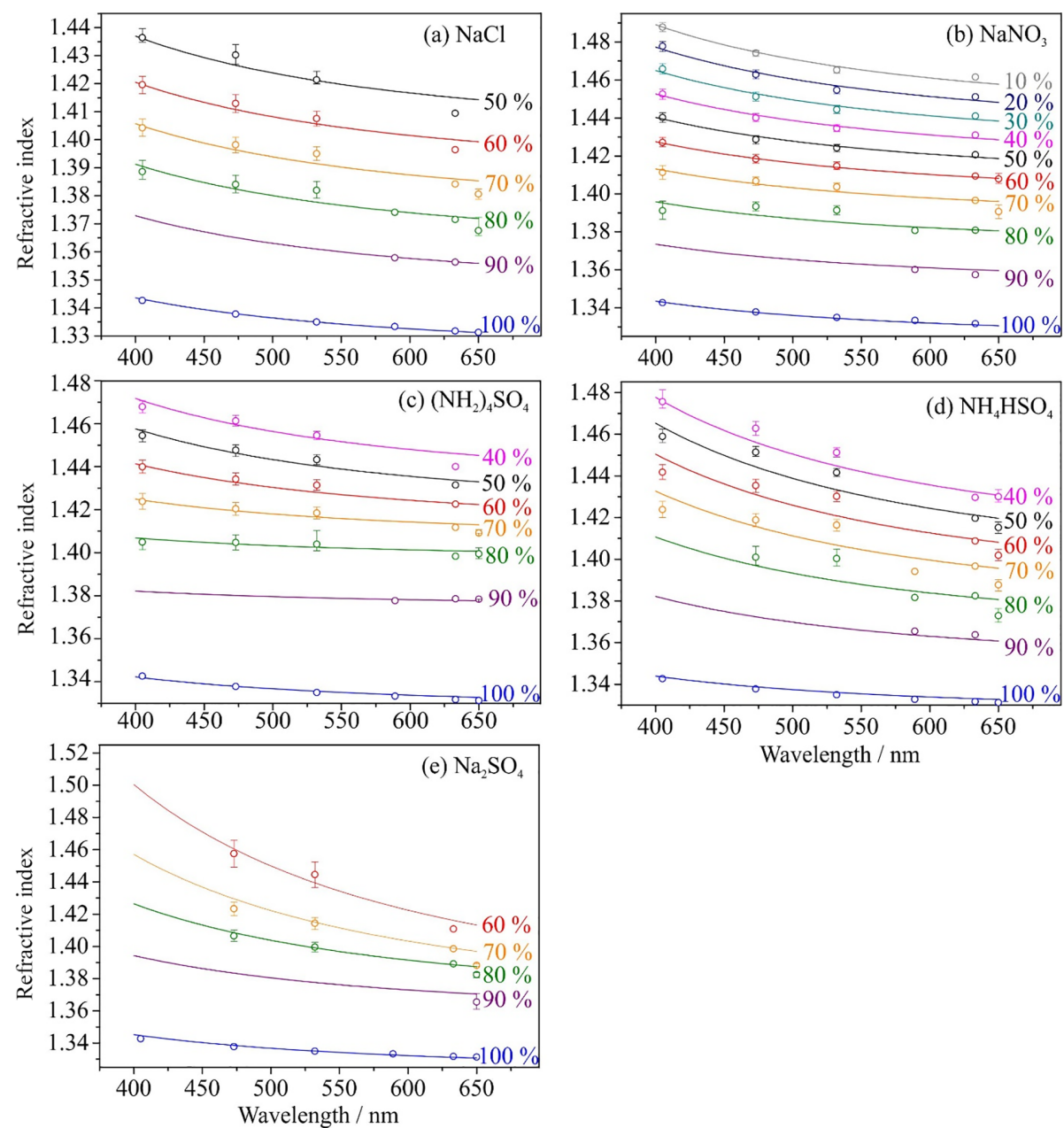

Figure 8. The best-fit Cauchy dispersion curves (solid lines) for measured and literature RI data (points) shown at $10 \%$ RH intervals (labels). The parameterisations were fitted to data at $2 \% \mathrm{RH}$ intervals, and the total numbers of data points included in the parameterisation are specified in Table 2. The curves are found by a global fit of the Cauchy dispersion model (Eqs. 7-9) to the measured and literature data in Fig. 5 using the procedure described in the text. The error bars represent the uncertainty in the RH measurements, indicated in the text, in the RI domain.

the $\pm 2 \%$ uncertainty associated with RH measurements in the $n_{\lambda}$ domain. Within these error bars, there is generally good agreement between the measured data and the Cauchy model. In all cases (except $\mathrm{NH}_{4} \mathrm{HSO}_{4}$, as previously discussed) the Cauchy model describes the measured $n_{405}, n_{473}$ and $n_{532}$ data well. There is good agreement between $n_{633}$ data and the Cauchy model at high RH. However, the literature $n_{633}$ values are lower than the calculated $n_{633}$ for $\mathrm{NaCl}$ and $\left(\mathrm{NH}_{2}\right)_{4} \mathrm{SO}_{4}$ at low $\mathrm{RH}$. These discrepancies are attributed to the reduced number of literature and measured data points for $\lambda>600 \mathrm{~nm}$ at the low RHs. The bulk $n_{589}$ data points are described well by the Cauchy model; two of the $\mathrm{NH}_{4} \mathrm{HSO}_{4}$ measured $n_{589}$ values are lower than the modelled $n_{589}$. The $n_{650}$ values from AOT measurements lie marginally lower than is expected from the Cauchy model. This is also evident in Fig. 3 in which AOT measurements (calculated at $n_{633}$ ) were compared to those parameterised by Tang et al. and implies that the RHs reported for each of the $n_{650}$ AOT measurements are systematically low by a value close to the $2 \%$ uncertainty associated with the $\mathrm{RH}$ measurements.

The overall agreement between the global Cauchy fit $\left(n_{\mathrm{fit}}\right)$ and the measured and literature values $\left(n_{j}\right)$ is quantified by evaluating the mean RI difference:

$\overline{|\Delta n|}=\frac{1}{J} \sum_{j=1}^{J}\left|n_{\mathrm{fit}}-n_{j}\right|$,

in which the summation is over all $J$ measured-literature values. Table 2 summarises the values of $\overline{|\Delta n|}$ for the inorganic solutes studied here. The solutes $\mathrm{NaCl}, \mathrm{NaNO}_{3}$ and $\left(\mathrm{NH}_{4}\right)_{2} \mathrm{SO}_{4}$ have values of $\overline{|\Delta n|} \leq 0.002$, which indicates that the measured and literature data points lie very close to the Cauchy parameterisation. The solutes $\mathrm{Na}_{2} \mathrm{SO}_{4}$ and 
$\mathrm{NH}_{4} \mathrm{HSO}_{4}$ give $\overline{|\Delta n|} \approx 0.003$ and $\overline{|\Delta n|} \approx 0.0044$, respectively. The limited number of measured and literature data for $\mathrm{Na}_{2} \mathrm{SO}_{4}$ is a consequence of the high efflorescence $\mathrm{RH}$ and results in an RI description that is not as well constrained, which is reflected in the $\overline{|\Delta n|}$ value.

\section{Conclusions}

Comprehensive $\sigma_{\mathrm{ext}}$ and PF measurements are reported for the hygroscopic response of aqueous droplets containing inorganic solutes of $\mathrm{NaCl}, \mathrm{NaNO}_{3},\left(\mathrm{NH}_{4}\right)_{2} \mathrm{SO}_{4}, \mathrm{NH}_{4} \mathrm{HSO}_{4}$ or $\mathrm{Na}_{2} \mathrm{SO}_{4}$, using either 405 or $532 \mathrm{~nm}$ SP-CRDS. These measurements permitted RI retrieval at wavelengths of 405, 473 and $532 \mathrm{~nm}$. The $n_{\lambda}$ retrieved from PFs when using a Gaussian laser beam, at 473 or $633 \mathrm{~nm}$ with a $\sim 30$ or $\sim 15 \mu \mathrm{m}$ beam waist, respectively, had twice the precision compared to PFs illuminated with a BB (at $532 \mathrm{~nm}$ ). The addition of a probe Gaussian-profile laser beam for retrieving particle size and $n_{\lambda}$ from PFs improves the precision and accuracy of $n_{\lambda}$ retrievals from $\sigma_{\text {ext }}$ measurements. Importantly, the precision in all RI retrievals is considerably better than the typical \pm 0.02 precision of aerosol ensemble CRDS measurements (Mason et al., 2012).

A Cauchy dispersion model provided an effective parameterisation of our measured (and literature) RI data in terms of both wavelength, from 400 to $650 \mathrm{~nm}$, and RH, $100 \%$ to efflorescence RH (Eqs. 7-9), with Table 2 reporting the best-fit coefficients. This represents the most precise and comprehensive description of RI of inorganic atmospheric aerosol to date. These parameterisations will be useful to researchers wishing to calculate the refractive indices of aerosol containing the main inorganic species found in atmospheric aerosol, for example in the calculation of radiative forcing efficiency or in the interpretation of measurements made by optical instruments.

Data availability. The experimental data presented in this paper are provided through the University of Bristol data repository at Bzdek et al. (2017).

Author contributions. MIC and REW contributed equally to the data presented in this work. JPR and AJOE designed the instruments described in this work. BRB assisted with optical tweezer measurements and all co-authors contributed to the preparation of the paper.

Competing interests. The authors declare that they have no conflict of interest.

Acknowledgements. Jonathan P. Reid acknowledges financial support from the EPSRC through a Leadership Fellowship
(EP/G007713/1). Michael I. Cotterell acknowledges funding from NERC (NE/J01754X/1) and the RSC through an Analytical Trust Fund studentship and support from the Aerosol Society in the form of a CN Davies award. Rose E. Willoughby acknowledges funding from NERC GW4+ DTP (NE/L002434/1) and support from the Aerosol Society in the form of the CN Davies award. Bryan R. Bzdek acknowledges support from the EPSRC (EP/L010569/1).

Edited by: Anne Perring

Reviewed by: two anonymous referees

\section{References}

AIM: Extended AIM Aerosol Thermodynamics Model: Model III, http://www.aim.env.uea.ac.uk/aim/model3/mod3rhw.php (last access: 5 January 2016), 2017.

Alexander, N., Allen, S., Stocker, T. F., Qin, D., Plattner, G.-K., Trignor, M. M. B., Boschung, J., Xia, Y., Bex, V., and Midgley, P. M.: The Physical Science Basis. Contribution of Working Group I to the Fifth Assessment Report of the Intergovernmental Panel on Climate Change, edited by: Stocker, T. F., Qin, D., Plattner, G.-K., Tignor, M., Allen, S. K., Boschung, J., Nauels, A., Xia, Y., Bex, V., and Midgley, P. M., Cambridge University Press, Cambridge, United Kingdom and New York, NY, USA, 1535 pp., https://doi.org/10.1017/CBO9781107415324, 2013.

Baynard, T., Lovejoy, E. R., Pettersson, A., Brown, S. S., Lack, D., Osthoff, H., Massoli, P., Ciciora, S., Dube, W. P., and Ravishankara, A. R.: Design and Application of a Pulsed Cavity Ring-Down Aerosol Extinction Spectrometer for Field Measurements, Aerosol Sci. Technol., 41, 447-462, https://doi.org/10.1080/02786820701222801, 2007.

Bohren, C. F. and Huffman, D. R.: Absorption and Scattering of Light by Small Particles, New York, Wiley, 1998.

Bzdek, B. R., Willoughby, R., Orr-Ewing, A. J., and Reid, J. P.: A Complete Parameterization of the Relative Humidity and Wavelength Dependence of the Refractive Index of Hygroscopic Inorganic Aerosol Particles, University of Bristol, https://doi.org/10.5523/bris.vpjfc3vxhkcb2nfc17b1sly54, 2017.

Carruthers, A. E., Walker, J. S., Casey, A., Orr-Ewing, A. J., and Reid, J. P.: Selection and Characterization of Aerosol Particle Size using a Bessel Beam Optical Trap for Single Particle Analysis, Phys. Chem. Chem. Phys., 14, 6741-6748, https://doi.org/10.1039/c2cp40371d, 2012.

Clegg, S. L., Brimblecombe, P., and Wexler, A. S.: A thermodynamic model of the system $\mathrm{H}^{+}-\mathrm{NH}_{4}^{+}-\mathrm{Na}^{+}-\mathrm{SO}_{42}-\mathrm{NO}_{3}^{-}$$\mathrm{Cl}^{-}-\mathrm{H}_{2} \mathrm{O}$ at $298.15 \mathrm{~K}$, J. Phys. Chem. A, 102, 2155-2171, https://doi.org/10.1021/jp973043j, 1998.

Cohen, M. D., Flagan, R. C., and Seinfeld, J. H.: Studies of concentrated electrolyte solutions using the electrodynamic balance, 1. Water activities for single-electrolyte solutions, J. Phys. Chem., 91, 4563-4574, https://doi.org/10.1021/j100301a029, 1987.

Cotterell, M. I., Preston, T. C., Mason, B. J., Orr-Ewing, A. J., and Reid, J. P.: Extinction Cross Section Measurements for a Single Optically Trapped Particle, Proc. SPIE, 9548, 11 pp., https://doi.org/10.1117/12.2189174, 2015a.

Cotterell, M. I., Mason, B. J., Preston, T. C., Orr-Ewing, A. J., and Reid, J. P.: Optical Extinction Efficiency Measurements on Fine 
and Accumulation Mode Aerosol Using Single Particle Cavity Ring-Down Spectroscopy, Phys. Chem. Chem. Phys., 17, 1584315856, https://doi.org/10.1039/C5CP00252D, 2015b.

Cotterell, M. I., Preston, T. C., Orr-Ewing, A. J., and Reid, J. P.: Assessing the Accuracy of Complex Refractive Index Retrievals from Single Aerosol Particle Cavity RingDown Spectroscopy, Aerosol Sci. Technol., 50, 1077-1095 https://doi.org/10.1080/02786826.2016.1219691, 2016.

Daimon, M. and Masumura, A.: Measurement of the refractive index of distilled water from the near-infrared region to the ultraviolet region, Appl. Opt., 46, 3811-3820, https://doi.org/10.1364/AO.46.003811, 2007.

David, G., Esat, K., Ritsch, I., and Signorell, R.: Ultraviolet Broadband Light Scattering for Optically-Trapped Submicron-Sized Aerosol Particles, Phys. Chem. Chem. Phys., 18, 5477-5485, https://doi.org/10.1039/C5CP06940H, 2016.

Davies, J. F. and Wilson, K. R.: Raman Spectroscopy of Isotopic Water Diffusion in Ultraviscous, Glassy, and Gel States in Aerosol by Use of Optical Tweezers, Anal. Chem., 88, 23612366, https://doi.org/10.1021/acs.analchem.5b04315, 2016.

Dinar, E., Abo Riziq, A., Spindler, C., Erlick, C., Kiss, G., and Rudich, Y.: The complex refractive index of atmospheric and model humic-like substances (HULIS) retrieved by a cavity ring down aerosol spectrometer (CRD-AS), Faraday Discuss., 137, 279-295, https://doi.org/10.1039/b703111d, 2008.

Erlick, C., Abbatt, J. P. D., and Rudich, Y.: How Different Calculations of the Refractive Index Affect Estimates of the Radiative Forcing Efficiency of Ammonium Sulfate Aerosols, J. Atmos. Sci., 68, 1845-1852, https://doi.org/10.1175/2011JAS3721.1, 2011.

Flores, J. M., Washenfelder, R. A., Adler, G., Lee, H. J., Segev, L., Laskin, J., Laskin, A., Nizkorodov, S. A., Brown, S. S., and Rudich, Y.: Complex refractive indices in the nearultraviolet spectral region of biogenic secondary organic aerosol aged with ammonia, Phys. Chem. Chem. Phys., 16, 10629-42, https://doi.org/10.1039/c4cp01009d, 2014a.

Flores, J. M., Zhao, D. F., Segev, L., Schlag, P., Kiendler-Scharr, A., Fuchs, H., Watne, A. K., Bluvshtein, N., Mentel, T. F., Hallquist, M., and Rudich, Y.: Evolution of the complex refractive index in the UV spectral region in ageing secondary organic aerosol, Atmos. Chem. Phys., 14, 5793-5806, https://doi.org/10.5194/acp14-5793-2014, 2014b.

Haddrell, A. E., Miles, R. E. H., Bzdek, B. R., Reid, J. P., Hopkins, R. J., and Walker, J. S.: Coalescence Sampling and Analysis of Aerosols using Aerosol Optical Tweezers, Anal. Chem., 89, 2345-2352, https://doi.org/10.1021/acs.analchem.6b03979, 2017.

Hand, J. L. and Kreidenweis, S. M.: A New Method for Retrieving Particle Refractive Index and Effective Density from Aerosol Size Distribution Data, Aerosol Sci. Technol., 36, 1012-1026, https://doi.org/10.1080/02786820290092276, 2002.

Hargreaves, G., Kwamena, N. O. A., Zhang, Y. H., Butler, J. R., Rushworth, S., Clegg, S. L., and Reid, J. P.: Measurements of the equilibrium size of supersaturated aqueous sodium chloride droplets at low relative humidity using aerosol optical tweezers and an electrodynamic balance, J. Phys. Chem. A, 114, 18061815, https://doi.org/10.1021/jp9095985, 2010.

Haynes, W. M. (Ed.): Concentrative Properties of Aqueous Solutions: Density, Refractive Index, Freezing Point Depression, and
Viscosity, in: CRC Handbook of Chemistry and Physics, 123 $148,2015$.

Haywood, J. and Boucher, O.: Estimates of the Direct and Indirect Radiative Forcing due to Tropospheric Aerosols: A Review, Rev. Geophys., 38, 513-543, 2000.

Haywood, J. M. and Shine, K. P.: The effect of anthropogenic sulfate and soot aerosol on the clear sky planetary radiation budget, Geophys. Res. Lett., 22, 603-606, https://doi.org/10.1029/95GL00075, 1995.

Hess, M., Koepke, P., and Schult, I.: Optical Properties of Aerosols and Clouds: The Software Package OPAC, B. Am. Meteorol. Soc., 79, 831-844, https://doi.org/10.1175/15200477(1998)079<0831:OPOAAC>2.0.CO;2, 1998.

Kogelnik, H. and Li, T.: Laser beams and resonators, Proc. IEEE, 54, 1312-1329, https://doi.org/10.1109/PROC.1966.5119, 1966.

Lang-Yona, N., Rudich, Y., Segre, E., Dinar, E., and Abo-Riziq, A.: Complex refractive indices of aerosols retrieved by continuous wave-cavity ring down aerosol spectrometer, Anal. Chem., 81, 1762-1769, https://doi.org/10.1021/ac8017789, 2009.

Langridge, J. M., Richardson, M. S., Lack, D., Law, D., and Murphy, D. M.: Aircraft Instrument for Comprehensive Characterization of Aerosol Optical Properties, Part I: Wavelength-Dependent Optical Extinction and Its Relative Humidity Dependence Measured Using Cavity Ringdown Spectroscopy, Aerosol Sci. Technol., 45, 1305-1318, https://doi.org/10.1080/02786826.2011.592745, 2011.

Levoni, C., Cervino, M., Guzzi, R., and Torricella, F.: Atmospheric aerosol optical properties: a database of radiative characteristics for different components and classes, Appl. Opt., 36, 8031-8041, https://doi.org/10.1364/AO.36.008031, 1997.

Mason, B. J., King, S.-J., Miles, R. E. H., Manfred, K. M., Rickards, A. M. J., Kim, J., Reid, J. P., and Orr-Ewing, A. J.: Comparison of the Accuracy of Aerosol Refractive Index Measurements from Single Particle and Ensemble Techniques, J. Phys. Chem. A, 116, 8547-8556, https://doi.org/10.1021/jp3049668, 2012.

Mason, B. J., Walker, J. S., Reid, J. P., and Orr-Ewing, A. J.: Deviations from Plane-Wave Mie Scattering and Precise Retrieval of Refractive Index for a Single Spherical Particle in an Optical Cavity, J. Phys. Chem. A, 118, 2083-2088, https://doi.org/10.1021/jp5014863, 2014.

Mason, B. J., Cotterell, M. I., Preston, T. C., Orr-Ewing, A. J., and Reid, J. P.: Direct Measurements of the Optical Cross Sections and Refractive Indices of Individual Volatile and Hygroscopic Aerosol Particles, J. Phys. Chem. A, 119, 5701-5713, https://doi.org/10.1021/acs.jpca.5b00435, 2015.

Miles, R. E. H., Carruthers, A. E., and Reid, J. P.: Novel Optical Techniques for Measurements of Light Extinction, Scattering and Absorption by Single Aerosol Particles, Laser Photon. Rev., 5, 534-552, https://doi.org/10.1002/lpor.201000029, 2011a.

Miles, R. E. H., Rudić, S., Orr-Ewing, A. J., and Reid, J. P.: Sources of Error and Uncertainty in the Use of Cavity Ring Down Spectroscopy to Measure Aerosol Optical Properties, Aerosol Sci. Technol., 45, 1360-1375, https://doi.org/10.1080/02786826.2011.596170, 2011 b.

Miller, J. L. and Orr-Ewing, A. J.: Cavity Ring-Down Spectroscopy Measurement of Single Aerosol Particle Extinction, II. Extinction of Light by an Aerosol Particle in an Optical Cavity Excited by a cw Laser, J. Chem. Phys., 126, 174303, https://doi.org/10.1063/1.2723736, 2007. 
Moise, T., Flores, J. M., and Rudich, Y.: Optical Properties of Secondary Organic Aerosols and Their Changes by Chemical Processes, Chem. Rev., 115, 4400-4439, https://doi.org/10.1021/cr5005259, 2015.

Preston, T. C. and Reid, J. P.: Accurate and efficient determination of the radius, refractive index, and dispersion of weakly absorbing spherical particle using whispering gallery modes, Journal of the Optical Society of America B, 30, 2113-2122, 2013.

Preston, T. C. and Reid, J. P.: Angular Scattering of Light by a Homogeneous Spherical Particle in a Zeroth-Order Bessel Beam and its Relationship to Plane Wave Scattering, J. Opt. Soc. Am. A, 32, 1053-1062, https://doi.org/10.1364/JOSAA.32.001053, 2015

Ravishankara, A. R., Rudich, Y., and Wuebbles, D. J.: Physical Chemistry of Climate Metrics, Chem. Rev., 115, 3682-3703, https://doi.org/10.1021/acs.chemrev.5b00010, 2015.

Richardson, C. B. and Spann, J. F.: Measurement of the Water Cycle in a Levitated Ammonium Sulfate Particle, J. Aerosol Sci., 15, 563-571, 1984.

Tang, I. N. and Munkelwitz, H. R.: Water activities, densities, and refractive indices of aqueous sulfates and sodium nitrate droplets of atmospheric importance, J. Geophys. Res., 99, 18801-18808, 1994.
Tang, I. N., Tridico, A. C., and Fung, K. H.: Thermodynamic and optical properties of sea salt aerosols, J. Geophys. Res., 102, 23269-23275, 1997.

Walker, J. S., Carruthers, A. E., Orr-Ewing, A. J., and Reid, J. P.: Measurements of Light Extinction by Single Aerosol Particles, J. Phys. Chem. Lett., 4, 1748-1752, 2013.

Washenfelder, R. A., Flores, J. M., Brock, C. A., Brown, S. S., and Rudich, Y.: Broadband measurements of aerosol extinction in the ultraviolet spectral region, Atmos. Meas. Tech., 6, 861-877, https://doi.org/10.5194/amt-6-861-2013, 2013.

Zarzana, K. J., Cappa, C. D., and Tolbert, M. A.: Sensitivity of Aerosol Refractive Index Retrievals Using Optical Spectroscopy, Aerosol Sci. Technol., 48, 1133-1144, https://doi.org/10.1080/02786826.2014.963498, 2014.

Zhao, W., Dong, M., Chen, W., Gu, X., Hu, C., Gao, X., Huang, W., and Zhang, W.: Wavelength-resolved optical extinction measurements of aerosols using broad-band cavity-enhanced absorption spectroscopy over the spectral range of $445-480 \mathrm{~nm}$, Anal. Chem., 85, 2260-2268, https://doi.org/10.1021/ac303174n, 2013. 